Diabetologia 11, 255-260 (1975)

(c) by Springer-Verlag 1975

\title{
The Oxygen Transport System of Red Blood Cells during Diabetic Ketoacidosis and Recovery*
}

\author{
J. Ditzel and E. StandI
}

Section of Endocrinology, Department of Medicine and Clinical Chemistry, Aalborg Regional Hospital, Aalborg, Denmark, and Diabetes Research Unit and 3rd Medical Department, City Hospital Schwabing, Munich, Federal Republic of Germany

Received: December 16, 1974, and in revised form: April 7, 1975

Summary. Daily evaluations of 8 newly detected ketoacidotic diabetics showed the Bohr-effect of haemoglobin to be decreased by $50 \%$ while erythrocyte 2,3-DPG was decreased below $10 \mu$ moles/g Hb. 2,3-DPG correlated strongly with $\mathrm{pH}$ during acidosis and with plasma inorganic phosphate $(\mathrm{Pi})$ subsequently to the first insulin administration. Oxygen affinity of haemoglobin, measured as $\mathrm{P}_{50}$ act $\mathrm{pH}$, was unchanged in ketoacidosis compared to the time before discharge. After correction of acidosis, however, $\mathrm{P}_{50}$ act $\mathrm{pH}$ fell strikingly $(p<0.001)$ and remained decreased up to 7 days depending upon the resynthesis of 2,3-DPG in relation to Pi. The Hill-coefficient $\mathrm{n}$ reflecting the slope of the oxygen dissociation curve was diminished in ketoacidosis $(p<0.005)$, and decreased further after pH-normalization $(p<0.005)$. There was a close association of $\mathrm{n}$ with 2,3-DPG $(p<0.001)$ and additionally with $\mathrm{Pi}$ at 2,3-DPG-levels below $10 \mu$ moles/ $\mathrm{g}$ Hb. Based on these findings a decreased erythrocyte oxygen release of one fifth during acidosis and more than one third after $\mathrm{pH}$-correction can be hypothesised. In view of the intimate relation of $\mathbf{P i}_{i}$ to the oxygen transport system it is suggested that treatment of ketoacidosis should include $\mathrm{Pi}$ substitution.

Key words: Bohr effect, diabetes, erythrocyte 2,3-DPG, Hill-coefficient, ketoacidosis, oxygen affinity of whole blood, $\mathrm{P}_{50}$ act $\mathrm{pH}$, plasma inorganic phosphate.
It has been widely accepted that diabetic ketoacidosis is not likely to impair the oxygen delivery capacity of red blood cells, because a decrease in haemoglobin oxygen affinity by acidosis, i.e. the Bohr effect, will oppose the adverse shift of the oxygen haemoglobin equilibrium induced by the effect of acidosis on red cell 2,3-diphosphoglycerate (2,3-DPG) $[1,2,3,4,5]$. Recently, however, the implications of 2,3-DPG on the Bohr effect itself using in vitro techniques have emerged $[6,7,8,9,10]$, the Bohr effect being lower with decreasing erythrocyte 2,3-DPG. Hence, in diabetic ketoacidosis, where 2,3-DPG has been known to be strikingly decreased since the work of Guest and Rapoport in 1939 [11], variation of the Bohr effect has to be considered as a parameter for tissue oxygenation besides the commonly appreciated influence of decreasing 2,3-DPG concentrations in diminishing the oxygen release from the haemoglobin molecule $[12,13]$. In view of possibly occurring tissue hypoxia we investigated the oxygen transport system of red blood cells, including the shape of the oxygen dissociation curve (ODC) at various stages of ketoacidosis.

\section{Materials and Methods}

8 newly diagnosed juvenile diabetics in ketoacidosis were studied immediately after admission to the

* Supported by a grant of the Municipal of Aalborg, the Nordic Insulin Foundation and the Deutsche Forschungsgemeinschaft. hospital and thereafter each morning prior to breakfast and insulin treatment. Ketoacidosis was diagnosed clinically and confirmed by excessive ketonuria, lowered standard bicarbonate and arterial blood $\mathrm{pH}$ (See Table 1 for clinical details). None of the patients had severe anemia or an infection, or suffered from respiratory or renal insufficiency. Treatment was carried out in a conventional manner without the use of alkaline or phosphate containing solutions; all patients recovered.

Arterial blood samples were drawn anaerobically and assayed within 15 minutes for $\mathrm{pH}, \mathrm{pO}_{2}, \mathrm{pCO}_{2}$ and standard bicarbonate in a BMS-3 blood gas system (Radiometer A/S, Copenhagen, Denmark). Similarly the venous $\mathrm{pO}_{2}$ was analyzed. Venous blood was collected into heparinized syringes from a catheter the tip of which was placed $20 \mathrm{~cm}$ proximal to the cubital vein. Red cell indices were measured by means of a Coulter Counter (Coulter Electronics Ltd., Dunstable, England). Red cell 2,3-DPG concentration was determined according to Ericsson and de Verdier [14], and plasma inorganic phosphate $(\mathrm{Pi})$ as described by Parekh and Jung [15]. Blood glucose measurements were performed with the Technicon Auto Analyzer [16]. Oxygen dissociation curves were run in a Radiometer DCA-1 apparatus, the principles of which have been described in detail by Duvelleroy et al. [17]. This method has been shown to give results which are identical with those obtained by the mixing technique [18]. In addition, the $\mathrm{pH}$ of the blood was recorded 
Table 1. Clinical data on admission

\begin{tabular}{llllllllll}
\hline Patient & Age & Sex & $\begin{array}{l}\text { Duration } \\
\text { of } \\
\text { diabetes }\end{array}$ & art $\mathrm{pH}$ & $\begin{array}{l}\text { Standard } \\
\text { bicarbon- } \\
\text { ate } \\
(\mathrm{mmol} / 1)\end{array}$ & $\begin{array}{l}\mathrm{pCO}_{2} \\
(\mathrm{~mm} \mathrm{Hg})\end{array}$ & $\begin{array}{l}\mathrm{Hb} \\
(\mathrm{g} / 100 \mathrm{ml})\end{array}$ & $\begin{array}{l}\text { Blood } \\
\text { glucose } \\
(\mathrm{mmol} / \mathrm{l})\end{array}$ & $\begin{array}{l}\text { Level of } \\
\text { conscious- } \\
\text { ness }\end{array}$ \\
\hline 1. G.D. & 15 & $\mathrm{~F}$ & 0 & 7.22 & 13.0 & 27.5 & 16.2 & 34.0 & alert \\
2. N.H. & 54 & $\mathrm{~F}$ & 0 & 6.98 & 7.8 & 28.0 & 14.7 & 34.4 & somnolent \\
3. F.C. & 18 & $\mathrm{M}$ & 0 & 7.32 & 17.2 & 31.0 & 16.1 & 22.2 & alert \\
4. J.E.L. & 21 & $\mathrm{M}$ & 0 & 7.21 & 12.1 & 25.6 & 16.1 & 31.6 & alert \\
5. N.J.R. & 19 & $\mathrm{M}$ & 0 & 7.30 & 16.3 & 30.0 & 16.4 & 47.4 & alert \\
6. H.H.K. & 19 & $\mathrm{M}$ & 0 & 7.01 & 8.8 & 32.3 & 18.5 & 32.0 & somnolent \\
7. M.O.M. & 24 & $\mathrm{M}$ & 0 & 7.29 & 16.5 & 32.3 & 17.2 & 21.1 & alert \\
8. L.J.L. & 51 & $\mathrm{M}$ & 0 & 7.16 & 9.4 & 17.3 & 12.7 & 51.0 & alert \\
\hline
\end{tabular}

continuously during the oxygenation procedure. The linear regression equations between the $\log \mathrm{O}_{2}$ half saturation pressures as 'recorded by the analyzer and the corresponding $\mathrm{pH}$ values were computed for blood samples at different concentration ranges of 2,3-DPG, whereby the linear regression coefficient gives the Bohr factor $\frac{\Delta \log P_{50}}{\Delta \mathrm{pH}}[6]$. Oxygen affinity was expressed in its inverse relation as $\mathbf{P}_{50}$ at actual $\mathrm{pH}$ in vivo using various Bohr factors, as found for different concentration ranges of 2,3-DPG. The Hill-coefficient $\mathrm{n}$ as a measure of heme-heme interaction and therefore of the slope of the ODC was obtained from the empirical Hill equation [19]

$$
\frac{\mathrm{Y}}{1-\mathrm{Y}}=\mathrm{pO}_{2}{ }^{\mathrm{n}}
$$

where $\mathrm{Y}$ is fractional saturation of haemoglobin with oxygen and $\mathrm{pO}_{2}$ the corresponding value at constant $\mathrm{pH}$ and $\mathrm{pCO}_{2}$.

Student's $\mathrm{t}$ test was used for statistical analysis. Means, standard deviation (SD), linear regressions, correlation coefficients and significance tests were performed with formulae entered into a Compucorp calculator Series 300 (Computer Design Corporation, Los Angeles, Calif., USA).

\section{Results}

Measurements were performed as outlined in the Methods section in the 8 patients on 47 days. In order to demonstrate the changes occurring we have selected for statistical comparison the day of admission prior to therapy (Group I), the day after acidosis had been corrected, i.e. the $2^{\text {nd }}$ or $3^{\text {rd }}$ day after admission (Group II), and the day before discharge, usually 10 to 14 days after admission (Group III). Table 2 presents the mean values \pm SD on these days together with the p-values for significant differences.

As can be seen, standard bicarbonate and $\mathrm{pCO}_{2}$ were not yet normalized in Group II despite a normal blood $\mathrm{pH}$. The haemoglobin concentration fell to lower levels, while the state of metabolic control

Table 2. Mean values and SD of parameters measured in 8 newly detected diabetics during ketoacidosis (Group I), after correction of acidosis (Group II) and before discharge (Group III)

\begin{tabular}{|c|c|c|c|c|c|c|}
\hline & Group I & $\begin{array}{l}\text { P-value } \\
\text { I vs. II }\end{array}$ & Group II & $\begin{array}{l}\text { p-value } \\
\text { II vs. III }\end{array}$ & Group III & $\begin{array}{l}\text { p-value } \\
\text { I vs. III }\end{array}$ \\
\hline Art pH & $7.19 \pm 0.13$ & $<0.001$ & $7.41 \pm 0.06$ & N.S. ${ }^{\mathrm{a}}$ & $7.42 \pm 0.02$ & $<0.001$ \\
\hline Standard bicarbonate $\mathrm{mmol} / \mathrm{l}$ & $12.6 \pm 3.7$ & $<0.001$ & $20.8 \pm 3.6$ & $<0.005$ & $24.9 \pm 1.3$ & $<0.001$ \\
\hline $\mathrm{pCO}_{2}(\mathrm{~mm} \mathrm{Hg})$ & $28.0 \pm 4.9$ & N.S. ${ }^{\mathrm{a}}$ & $30.3 \pm 4.5$ & $<0.001$ & $39.6 \pm 3.2$ & $<0.001$ \\
\hline $\mathrm{Hb}(\mathrm{g} / 100 \mathrm{ml})$ & $16.0 \pm 1.7$ & $<0.001$ & $13.6 \pm 2.1$ & N.S." & $12.8 \pm 1.1$ & $<0.001$ \\
\hline $\mathrm{MCHC}(\mathrm{mmol} / \mathrm{l})$ & $21.5 \pm 0.8$ & N.S. ${ }^{\mathbf{a}}$ & $21.4 \pm 0.8$ & $<0.01$ & $20.6 \pm 0.5$ & $<0.01$ \\
\hline Blood glucose $(\mathrm{mmol} / \mathrm{l})$ & $34.2 \pm 10.6$ & $<0.001$ & $13.2 \pm 4.4$ & N.S. ${ }^{a}$ & $12.0 \pm 9.0$ & $<0.001$ \\
\hline $\mathrm{Pi}(\mathrm{mmol} / \mathrm{l})$ & $1.50 \pm 0.37$ & $<0.005$ & $0.67 \pm 0.31$ & $<0.005$ & $1.31 \pm 0.14$ & N.S. ${ }^{\mathrm{a}}$ \\
\hline 2,3-DPG ( $\mu$ moles/g Hb) & $6.66 \pm 3.62$ & $<0.01$ & $8.73 \pm 2.11$ & $<0.001$ & $17.10 \pm 1.70$ & $<0.001$ \\
\hline $\mathrm{P}_{50}$ act $\mathrm{pH}(\mathrm{mm} \mathrm{Hg})$ & $27.3 \pm 1.9$ & $<0.001$ & $23.5 \pm 2.0$ & $<0.001$ & $27.2 \pm 1.8$ & N.S. ${ }^{2}$ \\
\hline Hill-coefficient $n$ & $2.24 \pm 0.12$ & $<0.005$ & $2.04 \pm 0.14$ & $<0.001$ & $2.51 \pm 0.11$ & $<0.005$ \\
\hline Oxyhaemoglobin (\%) & $98.0 \pm 1.7$ & N.S. ${ }^{a}$ & $98.3 \pm 3.0$ & N.S. ${ }^{a}$ & $96.7 \pm 1.7$ & N.S. ${ }^{\mathrm{s}}$ \\
\hline Art. $\mathrm{pO}_{2}(\mathrm{~mm} \mathrm{Hg})$ & $101.3 \pm 6.4$ & $<0.001$ & $83.5 \pm 5.5$ & N.S. ${ }^{a}$ & $83.6 \pm 6.6$ & $<0.001$ \\
\hline Ven. $\mathrm{pO}_{2}(\mathrm{~mm} \mathrm{Hg})$ & $78.8 \pm 17.2$ & $<0.05$ & $60.1 \pm 16.1$ & $<0.005$ & $38.5 \pm 4.3$ & $<0.001$ \\
\hline a.v. difference of $\mathrm{pO}_{2}(\mathrm{~mm} \mathrm{Hg})$ & $22.5 \pm 10.6$ & N.S. ${ }^{a}$ & $23.4 \pm 15.8$ & $<0.005$ & $45.1 \pm 4.7$ & $<0.001$ \\
\hline
\end{tabular}

${ }^{a}$ N.S. = non significant 
improved. MCHC was decreased before discharge compared to Group I and II. Pi was initially elevated above the normal range - which is $1.13 \pm 0.10$ $\mathrm{mmol} / \mathrm{l}$ in this laboratory - then dropped to markedly decreased values immediately after treatment with insulin and fluid substitution had been started, not infrequently remaining at such low levels up to 7 days (e.g. patient N.H., see Fig. 1). At discharge Pi

$$
0=2,3-D P G
$$

- = plasma inorganic phosphate $\left(\mathrm{Pi}_{\mathrm{i}}\right)$

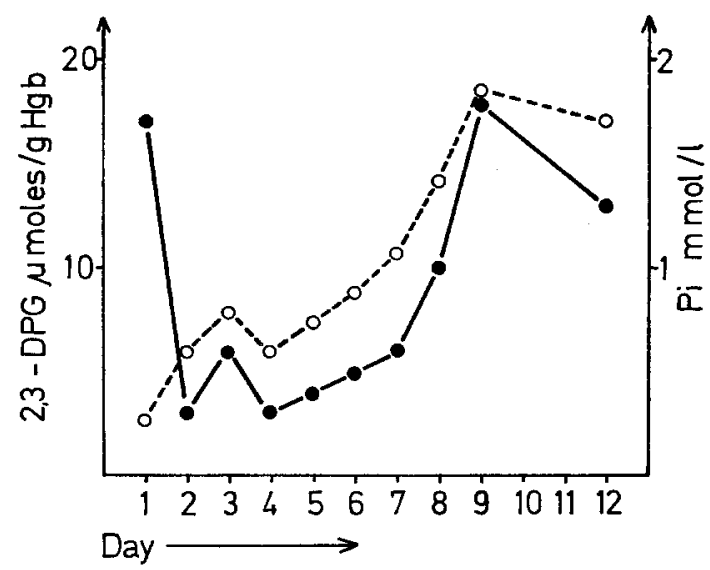

Fig. 1. Time course of recovery of 2,3-DPG in relation to plasma inorganic phosphate in patient N.H. this laboratory) in a close association with Pi (Table $3 ; p<0.001$ ). A significant relationship between the resynthesis of 2,3-DPG and Pi was found in each of the individual cases as exemplified for patient N.H. in Fig. 1. Mean $\mathrm{P}_{50}$ act $\mathrm{pH}$ on admission and at discharge did not differ from each other (Table 2, Group I and III). After correction of acidosis, however, $\mathbf{P}_{50}$ act $\mathrm{pH}$ fell strikingly and remained low for several days (Table 2, Group II). Furthermore, the shape of the ODC was altered as well. The Hill-coefficient $n$ was decreased already on admission (Table 2, Group I) and even more markedly after treatment had been started (Group II). There was a close correlation of $n$ with 2,3-DPG for all values determined (Table 3; $\mathrm{p}<0.001$ ) and with Pi for blood samples with a 2,3DPG content of less than $10 \mu$ moles/g Hb (Table 3;

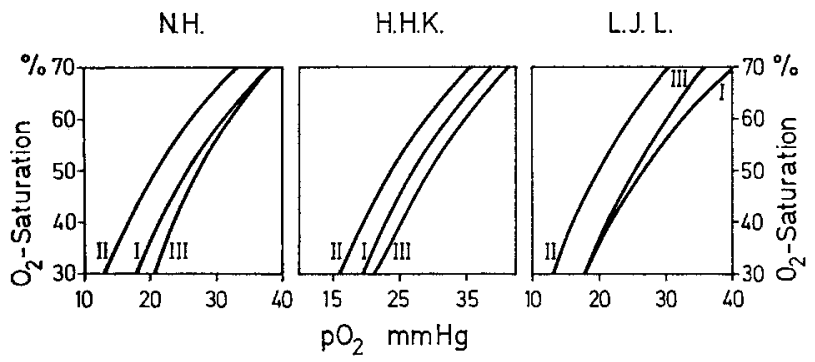

Fig. 2. The oxygen dissociation curves of the 3 most acidotic patients (N.H., H.H.K. and L.J.L.) in ketoacidosis (I), after correction of acidosis (II) and before discharge (III)

Table 3. Linear regression equations, correlation coefficients and statistical significance of correlations in 8 subjects during diabetic ketoacidosis and recovery

\begin{tabular}{|c|c|c|c|}
\hline Variables & Linear regression & $\begin{array}{l}\text { Correlation } \\
\text { coefficient }\end{array}$ & $\begin{array}{l}\text { Significance } \\
\text { p-value }\end{array}$ \\
\hline $\begin{array}{l}\text { All values }(\mathrm{n}=47) \\
\mathrm{Pi} / \mathrm{P}_{50} \text { act } \mathrm{pH} \\
2,3-\mathrm{DPG} / \mathrm{Hill} \mathrm{n}\end{array}$ & $\begin{array}{l}\mathrm{P}_{50} \text { act } \mathrm{pH}=3.29 \mathrm{Pi}+21.74 \\
\mathrm{n}=0.04 \mathrm{DPG}+1.83\end{array}$ & $\begin{array}{l}r=0.58 \\
r=0.71\end{array}$ & $\begin{array}{l}<0.001 \\
<0.001\end{array}$ \\
\hline $\begin{array}{l}\text { All values except } d \\
2,3-\mathrm{DPG} / \mathbf{P}_{50} \text { act } \mathrm{pl} \\
\mathrm{Pi} / 2,3-\mathrm{DPG}\end{array}$ & $\begin{array}{l}\text { ta on admission }(\mathrm{n}=39) \text { : } \\
\mathrm{P}_{50} \text { act } \mathrm{pH}=0.32 \mathrm{DPG}+20.62 \\
2,3-\mathrm{DPG}=7.16 \mathrm{Pi}+5.56\end{array}$ & $\begin{array}{l}r=0.55 \\
r=0.73\end{array}$ & $\begin{array}{l}<0.001 \\
<0.001\end{array}$ \\
\hline $\begin{array}{l}\text { During acidosis on } \\
\mathrm{pH} / 2,3-\mathrm{DPG} \\
\mathrm{pH} / \mathrm{Pi} \\
\mathrm{BG} / 2,3-\mathrm{DPG} \\
\text { 2,3-DPG/art } \mathrm{pO}_{2}\end{array}$ & $\begin{array}{l}y(n=19): \\
2,3-D P G=19.68 p H-134.77\end{array}$ & $\begin{array}{l}\mathrm{r}=0.72 \\
\mathrm{r}=0.42\end{array}$ & $\begin{array}{l}<0.001 \\
\text { N.S. } \\
\text { N.S. } \\
\text { N.S.a }\end{array}$ \\
\hline $\begin{array}{l}2,3-\mathrm{DPG}<10 \mu \mathrm{mo} \\
\mathbf{P i} / \mathrm{Hill} \mathrm{n}\end{array}$ & $\begin{array}{l}\mathrm{es} / \mathrm{g} \mathrm{Hb}(\mathrm{n}=18): \\
\mathrm{n}=0.31 \mathrm{Pi}+1.85\end{array}$ & $\mathrm{r}=0.71$ & $<0.001$ \\
\hline
\end{tabular}

a N. S. = non significant

was slightly increased again. Red cell 2,3-DPG concentration on admission averaged at a considerably decreased level of approximately $45 \%$ of the normal amount. Eventually 2,3-DPG rose to values above the normal range $(14.40 \pm 1.28$ for normal subjects in $p<0.001$ ), i.e. at low 2,3-DPG levels a high Pi opposed the decrease of n. Fig. 2 illustrates the alterations in the ODC for the 3 most acidotic patients. Arterial $\mathrm{pO}_{2}$ was initially elevated (Table 2); $\mathrm{pO}_{2}$ of mixed venous blood decreased gradually from markedly 
enhanced values on admission to the normal range at discharge (Table 2). The arteriovenous $\mathrm{pO}_{2}$ difference in Group $\mathrm{I}$ and II was only half of the amount at discharge (Group III).

$\mathrm{P}_{50}$ act $\mathrm{pH}$ was found to be closely associated both with 2,3-DPG and Pi. Arterial blood $\mathrm{pH}$ strongly influenced 2,3-DPG during ketoacidosis $(p<0.001)$. At the same time a correlation was present neither between blood glucose and 2,3-DPG nor between 2,3-DPG and arterial $\mathrm{pO}_{2}$ (Table 3).



Fig. 3. Correlation of $\log \mathbf{P}_{50}$ as recorded by the dissociation curve analyzer with the corresponding $\mathrm{pH}$. The linear regression coefficient gives the Bohr factor

Fig. 3 shows a plot of $\mathrm{pH}$ versus $\log \mathrm{P}_{50}$, both values as actually recorded by the ODC analyzer. The Bohr factor can be read as the linear regression coefficient. An approximately normal Bohr factor of -0.52 was obtained for blood samples with a 2,3-DPG concentration between 10 and $14 \mu$ moles/g $\mathrm{Hb}(p<$ 0.001 ), whereas at 2,3-DPG concentrations below 10 $\mu$ moles $/ \mathrm{g} \mathrm{Hb}-$ i.e. usually on admission in ketoacidosis - the Bohr factor was reduced to -0.24 ( $p<$ 0.001 ). The analogous linear regression for blood samples with a 2,3-DPG content above $14 \mu$ moles/g $\mathrm{Hb}$ was $y=0.48 \mathrm{x}+4.99 \quad(r=-0.61 ; p<0.01)$, which gives a Bohr factor of -0.48 .

\section{Discussion}

This study confirms the occurrence of abnormalities in the oxygen transport system of red blood cells in diabetic ketoacidosis and especially so during recovery. The decrement of 2,3-DPG was strongly defined by the arterial $\mathrm{pH}$ during acidosis, which is in good agreement with reports from others $[2,3]$. The linear regression of $\mathrm{pH}$ versus 2,3-DPG from the data obtained during acidosis in our patients showed an intercept at the normal $\mathrm{pH}$ of 7.4 at a 2,3-DPG concentration of about $11 \mu$ moles/g Hb - the mean of our normal range being $14.40 \pm 1.28$ - thus indicating that additional parameters play an important role in determining the 2,3-DPG concentration in this situation. It is suggested that $P i$ is at least one of these parameters, since resynthesis of 2,3-DPG was closely correlated with $\mathrm{Pi}$ after $\mathrm{Pi}$ had fallen to very low levels following therapy with insulin and fluids, as has been reported previously $[20,21]$.

The Bohr effect of haemoglobin, i.e. the reduction of oxygen affinity of haemoglobin by acidosis, has been shown to be dependent on 2,3-DPG in vitro by several investigators mainly using diluted haemoglobin solutions $[6,7,8,9,10]$. Fig. 3 suggests that these findings can be applied to human disease, e.g. diabetic ketoacidosis. At 2,3-DPG concentrations below 10 $\mu$ moles $/ \mathrm{g} \mathrm{Hb}$ (mean $7.07+2.11$ ), i.e. on admission in ketoacidosis and for some time thereafter, the Bohr factor amounted to only 50 per cent of the normal value of -0.48 . Considering that our clinical approach only allowed the evaluation of concentration ranges of 2,3-DPG and that we cannot totally discount other metabolic alterations in ketoacidosis and thereafter, our results agree favourably with data recorded in the literature $[10,22]$.

What implication does a decrease of the Bohr factor have? First of all, the Bohr effect is a mechanism by which more oxygen is delivered to tissue in the microcirculation at a given partial pressure of oxygen. Since the mean arteriovenous difference in $\mathrm{pH}$ is unaltered during ketoacidosis $(0.03 \pm 0.01$; Ditzel and Standl, unpublished data), the decrease of the Bohr effect seems not to be counteracted in this situation by a widening of the arterio-venous $\mathrm{pH}$ gap and should therefore result in a reduced oxygen availability for the body tissues. Secondly, the Bohr effect has to be considered in calculating the actual $P_{50}$ at in vivo $\mathrm{pH}$. Hence, it is not surprising that the values for $\mathrm{P}_{50}$ act $\mathrm{pH}$ found in our ketoacidotic subjects are somewhat lower than the ones previously reported [1]. Even so, the earlier observations that stated the $\mathrm{P}_{50}$ act $\mathrm{pH}$ not to be decreased in ketoacidosis are confirmed $[1,3]$. In comparison to the results obtained in our patients at discharge (Table 2, Group I and III) the effect of diminished 2,3-DPG concentrations on the $\mathrm{P}_{50}$ is virtually balanced by the lowered $\mathrm{pH}$ during acidosis. However, after correction of acidosis a disproportion between 2,3-DPG and $\mathrm{pH}$ becomes quite prominent, as reflected by the corresponding fall of $\mathrm{P}_{50}$ act $\mathrm{pH}$ (Table 2, and Fig. 2, Group II). In a close correlation with $\mathrm{Pi}$ it takes up to 1 week for 2,3- 
DPG to return to an approximately normal level (Fig. 1 ), and the $P_{50}$ will be impaired for the same period.

The Hill-coefficient $n$ which determines the slope of the ODC (usually $n$ equals about 2.6 in human blood) has been shown to be dependent upon the 2,3$\mathrm{DPG} / \mathrm{Hb}$ ratio in haemoglobin solutions in vitro [9]. A decrease of $n$ at low 2,3-DPG concentrations, comparable to the 2,3-DPG levels during ketoacidosis and after correction of acidosis in our patients, could be prevented by higher inorganic phosphate concentrations [9]. Again, our results appear to be in good agreement with these in vitro studies as suggested by the close correlation of $n$ with 2,3-DPG for all measurements and with $P i$ for blood samples containing a 2,3-DPG concentration less than $10 \mu \mathrm{moles} / \mathrm{g} \mathrm{Hb}$ (Table 3). This explains why $\mathrm{n}$ was somewhat diminished on admission in ketoacidosis, when low 2,3DPG concentrations were opposed by high Pi levels, and fell significantly further after $\mathrm{Pi}$ had dropped to a very low range (Table 2, Group I and II). As Benesch et al. have pointed out, this decrement in $\mathbf{n}$ might not reflect a truly reduced heme-heme interaction, but may rather be due to an integrated oxygen dissociation curve originating from the successive oxygenation of two haemoglobin species, i.e. 2,3-DPG devoid haemoglobin with high oxygen affinity and 2,3-DPG complexed haemoglobin with normal oxygen affinity [23].

Since the Hill-coefficient $\mathbf{n}$ expresses the slope of the ODC, a decrease of $\mathbf{n}$ indicates a flattening of the equilibrium curve, i.e. - somewhat simplified - relatively more oxygen will be delivered to tissues at a high $\mathrm{pO}_{2}$ and less at a medium or lower $\mathrm{pO}_{2}$. Whether this may be harmful for tissues operating at a lower $\mathrm{pO}_{2}$ or, conversely, whether it may comprise a beneficial adaptation to diminished 2,3-DPG levels during ketoacidosis and recovery in order to provide as much oxygen as possible at higher partial pressures of oxygen, is difficult to decide. In any case, the decrease of the arteriovenous $\mathrm{pO}_{2}$ difference and the high $\mathrm{pO}_{2}$ in mixed venous blood of our patients in acidosis and after correction (Table 2, Group I and II) could be consistent with a disordered oxygen delivery in the body at lower than high oxygen pressures.

Eventually an attempt shall be made to quantitate the observed alterations in $\mathrm{P}_{50}$ act $\mathrm{pH}$, the Hill-coefficient $\mathrm{n}$ and the in vivo effective Bohr effect in terms of oxygen availability for tissues operating at different $\mathrm{pO}_{2}$-intervals (Table 4). Computing the mean ODC for the situation in ketoacidosis, after correction of acidosis and before discharge and deriving therefrom the respective oxygen unloading, can only be understood as a crude approximation, because several assumptions had to be made, e.g. 1) a constant acidifi-
Table 4. Oxygen unloading in per cent of the total oxygen carrying capacity of blood as a consequence of changes in the $O D C$ and in the Bohr effect during ketoacidosis (Group I), after correction of acidosis (Group II) and before discharge (Group III) in respect to tissues operating at different $\mathrm{pO}_{2}$ intervals

\begin{tabular}{llcl}
\hline $\mathrm{pO}_{2}$-interval & \multicolumn{3}{l}{$\%$ \% unloading of total oxygen } \\
$\mathrm{mm} \mathrm{Hg}$ & carried by blood & III \\
\hline$\Delta 60$ to 50 & 11 & 9.5 & 12.5 \\
$\Delta 40$ to 30 & 19 & 15 & 24 \\
$\Delta 20$ to 15 & 17 & 16.5 & 19 \\
\hline
\end{tabular}

cation of $0.1 \mathrm{pH}$ at the tissue level and 2) that no other adaptive changes would take place. Nevertheless Table 4 should give an impression of the magnitude of the fluctuations occurring in our patients. As may be seen, the most marked alterations were found at a medium $\mathrm{pO}_{2}$, which would be pertinent for many tissues in vivo. When the oxygen tensions fall from 40 to $30 \mathrm{~mm} \mathrm{Hg}$ at the tissue level, $24 \%$ of the total oxygen carried by the blood would be released from the erythrocytes in the approximately normal situation at discharge. This amount is diminished by one fifth in ketoacidosis and more than one third after correction of acidosis. Interestingly, at high and low $\mathrm{pO}_{2}$ only minor changes occur.

Of course one has to realize that the oxygen transport system is but one major parameter involved in tissue oxygenation. Peripheral oxygen supply is also governed by local blood flow, haemoglobin concentration and oxyhaemoglobin saturation. Whereas the latter two factors were not decreased in our patients (Table 2), an impaired local blood flow could be an important participating event in the reduction of peripheral oxygen extraction. Indeed, biomicroscopic observations and photometric measurements have shown the subcutaneous microvessels of the bulbar conjunctivae to be constricted during severe ketoacidosis and most true capillaries to be closed [24]. Thus, the circulating blood by-passed the tissue through shunt vessels. These findings are not inconsistent with reports of an increased overall blood flow in muscle-, adipose- and cutaneous-tissues during acidosis [25].

In view of this abnormal microvascular reaction and of the disordered erythrocyte oxygen transport system described in this paper it is conceivable that hypoxic tissue injuries might occur during diabetic ketoacidosis and recovery. In order to combat this problem an effective therapeutic approach seems to be warranted. The intimate relation of $P i$ with 2,3DPG and other parameters determining the oxygen haemoglobin equilibrium gives good reason for adding 
phosphate to i.v. replacement regimens in ketoacidosis, as recommended many years ago [26] and more recently by us $[20,21]$ and others $[3,4]$.

\section{References}

1. Bellingham, A. J., Detter, J. C., Lenfant, C.: The role of haemoglobin oxygen affinity and red cell 2,3-DPG in the management of diabetic ketoacidosis. Trans. Ass. Amer. Phycns 83, 113-120 (1970)

2. Bellingham, A. J., Detter, J. C., Lenfant, C.: Regulatory mechanisms of haemoglobin oxygen affinity in acidosis and alkalosis. J. clin. Invest. 50, 700-706 (1971)

3. Alberti, K. G. M. M., Darley, J. H., Emerson, P. M., Hockaday, T. D. R.: 2,3-diphosphoglycerate and tissue oxygenation in uncontrolled diabetes mellitus. Lancet 1972 II, 391-395

4. Hockaday, T. D. R., Alberti, K. G. M. M.: Diabetic coma. Clin. Endocr. Metabol. 1, $751-788$ (1972)

5. King, A. J., Cooke, N. J., McCuish, A., Clarke, B. F., Kirby, B. F.: Acid-base changes during treatment of diabetic ketoacidosis. Lancet 1974 I, 478 - 481

6. Bauer, Ch.: Antagonistic influence of $\mathrm{CO}_{2}$ and 2,3- diphosphoglycerate on the Bohr effect of human haemoglobin. Life Sci. 8, 1041-1046 (1969)

7. Benesch, R. E., Benesch, R., Yu, C. I.: The Oxygenation of haemoglobin in the presence of 2,3-diphosphoglycerate. Effect of temperature, $\mathrm{pH}$, ionic strength, and haemoglobin concentration. Biochemistry 8, 2567-2571 (1969)

8. Siggaard-Andersen, O., Salling, N.: Oxygen-linked hydrogen ion binding of human haemoglobin. Effect of carbon dioxide and 2,3-diphosphoglycerate. II. Studies on whole blood. Scand. J. clin. Lab. Invest. 27, 361-366 (1971)

9. Tomita, S., Riggs, A.: Studies of the interaction of 2,3diphosphoglycerate and carbon dioxide with hemoglobins from mouse, man, and elephant. J. biol. Chem. 246, 547554 (1971)

10. Duhm, J.: 2,3-DPG-induced displacements of the oxyhemoglobin dissociation curve of blood: mechanism and consequences. In: Oxygen transport to tissue (eds. H. I. Bicher, D. F. Bruley), pp. 179-186. New York: Plenum Publishing Corporation 1972

11. Guest, G. M., Rapoport, S.: Role of acid-soluble phosphorus compounds in red blood cells. Amer. J. Dis. Child. 58, 1078-1089 (1939)

12. Benesch, R., Benesch, R. E.: The effect of organic phosphates from the human erythrocytes on the allosteric properties of hemoglobin. Biochem. biophys. Res. Commun. 26, 162-167 (1967)
13. Chanutin, A., Curnish, R. R.: Effect of organic and inorganic phosphates on the oxygen equilibrium of human erythrocytes. Arch. Biochem. 121, 96-102 (1967)

14. Ericsson, A., de Verdier, C. H.: A modified method for the determination of 2,3-diphosphoglycerate in erythrocytes. Scand. J. clin. Lab. Invest. 29, 85-90 (1972)

15. Parekh, A. C., Jung, D. H.: Serum inorganic phosphorus determination using p-phenylene-diamine as a reducing agent. Clin. chim. Acta 27, 373-377 (1970)

16. Bergmeyer, H. U., Bernt, E., Lachenicht, R.: In: Methoden der enzymatischen Analyse (2nd ed. H. U. Bergmeyer) pp. 1181-1185. Weinheim: Verlag Chemie 1970

17. Duvelleroy, M. A., Buckles, R. C., Rosenkaimer, S., Tung, C., Laver, M. A.: An oxyhemoglobin dissociation analyzer. J. appl. Physiol. 28, 227-233 (1970)

18. Bellingham, A. J., Lenfant, C.: Hb affinity for $\mathrm{O}_{2}$ determined by $\mathrm{O}_{2}-\mathrm{Hb}$ dissociation analyzer and mixing technique. J. appl. Physiol. 30, 903-904 (1971)

19. Hill, A. V.: J. Physiol. (Lond.) 40, 4-7 (1910)

20. Ditzel, J.: Effect of plasma inorganic phosphate on tissue oxygenation during recovery from diabetic ketoacidosis. Advanc. Exp. Med. Biol. 37 A, 163-172 (1973)

21. Ditzel, J.: Importance of plasma inorganic phosphate on tissue oxygenation during recovery from diabetic ketoacidosis. Horm. Metabol. Res. 5, $471-472$ (1973)

22. Arturson, G., Garby, L., Robert, M., Zaar, B.: The oxygen dissociation curve of normal human blood with special reference to the influence of physiological effector ligands. Scand. J. clin. Lab. Invest. 34, 9-13 (1974)

23. Benesch, R., Benesch, R. E., Yu, C. J.: Reciprocal binding of oxygen and diphosphoglycerate by human hemoglobin. Proc. nat. Acad. Sci. (Wash.) 59, 526-532 (1968)

24. Heuer, H. E., Ditzel, J.: Microvascular observations in relation to oxygen tension studies in controlled and uncontrolled diabetics. Acta endocr. (Kbh.) Suppl. 181, 5 (1973)

25. Gundersen, H. J. G.: Peripheral blood flow and metabolic control in juvenile diabetes. Diabetologia 10, 225-231 (1974)

26. Franks, M., Berris, R. F., Kaplan, N. O., Myers, G. B.: Metabolic studies in diabetic acidosis. II. The effect of the administration of sodium phosphate. Arch. Intern. Med. 81, 42-55 (1948)

Dr. E. Standl

Forschergruppe Diabetes

Institut für Diabetesforschung

8 München 40

Kölner Platz 1

Federal Republic of Germany 